\title{
Artemisinin triggers induction of cell-cycle arrest and apoptosis in Leishmania donovani promastigotes
}

\begin{abstract}
Correspondence
Mitali Chatterjee

ilatim@vsnl.net
\end{abstract}

Received 26 April 2007

Accepted 22 May 2007
Rupashree Sen, ${ }^{1}$ Samiran Bandyopadhyay, ${ }^{2}$ Avijit Dutta, ${ }^{1}$ Goutam Mandal, ${ }^{1}$ Sudipto Ganguly, ${ }^{1}$ Piu Saha ${ }^{1}$ and Mitali Chatterjee ${ }^{1}$

\author{
${ }^{1}$ Department of Pharmacology, Institute of Postgraduate Medical Education \& Research, \\ 244 B Acharya J. C. Bose Road, Kolkata 700 020, India \\ ${ }^{2}$ National Research Centre on Yak, Indian Council of Agricultural Research, Dirang, \\ Arunachal Pradesh 790101, India
}

\begin{abstract}
A major impediment to effective anti-leishmanial chemotherapy is the emergence of drug resistance, especially to sodium antimony gluconate, the first-line treatment for leishmaniasis. Artemisinin, a sesquiterpene lactone isolated from Artemisia annua, is an established anti-malarial compound that showed anti-leishmanial activity in both promastigotes and amastigotes, with $\mathrm{IC}_{50}$ values of 160 and $22 \mu \mathrm{M}$, respectively, and, importantly, was accompanied by a high safety index ( $>22$-fold). The leishmanicidal activity of artemisinin was mediated via apoptosis as evidenced by externalization of phosphatidylserine, loss of mitochondrial membrane potential, in situ labelling of DNA fragments by terminal deoxyribonucleotidyltransferase-mediated dUTP nick end labelling (TUNEL) and cell-cycle arrest at the sub- $\mathrm{G}_{0} / \mathrm{G}_{1}$ phase. Taken together, these data indicate that artemisinin has promising anti-leishmanial activity that is mediated by programmed cell death and, accordingly, merits consideration and further investigation as a therapeutic option for the treatment of leishmaniasis.
\end{abstract}

\section{INTRODUCTION}

Leishmania, a unicellular trypanosomatid protozoan parasite, is the causative organism of leishmaniasis, which comprises a wide disease spectrum ranging from localized, self-healing, cutaneous lesions to disfiguring mucocutaneous leishmaniasis and the visceral form, which can be fatal if neglected (Murray et al., 2005). In the past decade, an unprecedented increase in unresponsiveness to antimonials, the first line of treatment, in visceral leishmaniasis has been observed, importantly in the Indian subcontinent, a major endemic area of visceral leishmaniasis (Croft et al., 2006). In the absence of an effective vaccine, chemotherapy remains the sole weapon in the arsenal against leishmaniasis (Murray et al., 2005). Current treatment modalities are limited, have the potential to develop resistance and possess unacceptable toxicity (Sundar \& Chatterjee, 2006).

In the ongoing search for better leishmanicidal compounds, plant-derived products are gaining ground (Dutta et al., 2007a, b; Sen et al., 2007). Artemisinin, a sesquiterpene endoperoxide isolated from Artemisia annua, is an estab-

Abbreviations: MTS, 3-(4, 5-dimethylthiazol-2-yl)-5-(3-carboxymethaloxyphenyl)-2-(4-sulfonyl)-2H-tetrazolium inner salt; PI, propidium iodide; TdT, terminal deoxynucleotidyl transferase; TUNEL, TdT-mediated dUTP nick end labelling. lished anti-malarial drug (Bhakuni et al., 2001; Meshnick, 2002). However, there has only been one study investigating its anti-leishmanial activity (Yang \& Liew, 1993), where its efficacy against experimental cutaneous leishmaniasis was demonstrated. Studies of the efficacy of artemisinin against Leishmania donovani, the causative organism of visceral leishmaniasis, have been restricted to promastigotes (Avery et al., 2003), and studies of its efficacy in amastigotes, the biologically relevant form, are notably absent. The antileishmanial activity of an ethanolic extract of the leaves of Artemisia indica was investigated in exponential-phase promastigotes from six strains responsible for cutaneous, mucocutaneous or visceral leishmaniasis and the $\mathrm{IC}_{50}$ values ranged from 0.21 to $0.58 \mathrm{mg} \mathrm{ml}^{-1}$ (Ganguly et al., 2006a). Accordingly, the current study was undertaken to establish the leishmanicidal efficacy of artemisinin in L. donovani, and to demonstrate the high safety index of the drug and delineate the molecular mechanisms that contribute to the observed leishmanicidal activity.

\section{METHODS}

Chemicals. All chemicals used were of analytical grade. RPMI 1640 was obtained from Gibco-BRL, methanol and ethanol from Merck, 5,5',6,6' -tetrachloro-1, $1^{\prime}, 3,3^{\prime}$-tetraethylbenzimidazolylcarbocyanine iodide (JC-1) from Molecular Probes, FITC-conjugated annexin V 
from BD Biosciences and a Cell Death Detection kit from Roche. All other chemicals were from Sigma. A $200 \mathrm{mM}$ stock solution of artemisinin was prepared in tissue-culture-grade DMSO and stored at $-20{ }^{\circ} \mathrm{C}$; miltefosine and pentamidine were freshly prepared in M199 medium (serum-free).

Parasite culture. Promastigotes of $L$. donovani strain MHOM/IN/ 83/AG83 were routinely cultured at $24{ }^{\circ} \mathrm{C}$ in $\mathrm{M} 199$ medium supplemented with $10 \%$ fetal calf serum, $50 \mathrm{U}$ penicillin $\mathrm{ml}^{-1}$ and $50 \mu \mathrm{g}$ streptomycin $\mathrm{ml}^{-1}$, and subcultured every $72 \mathrm{~h}$ using an inoculum of $1 \times 10^{6}$ cells $\mathrm{ml}^{-1}$.

Cell line culture. A non-adherent human monocyte cell line, THP1, obtained from the National Centre for Cell Sciences (Pune, India), was maintained in RPMI 1640 supplemented with $10 \%$ fetal calf serum, $50 \mathrm{U}$ penicillin $\mathrm{ml}^{-1}$ and $50 \mu \mathrm{g}$ streptomycin $\mathrm{ml}^{-1}$ at $37{ }^{\circ} \mathrm{C}$, $5 \% \mathrm{CO}_{2}$. The cells were subcultured every $72 \mathrm{~h}$ using an inoculum of $2 \times 10^{5}$ cells $\mathrm{ml}^{-1}$.

In vitro evaluation of anti-promastigote activity. The antileishmanial activity of artemisinin was initially established in promastigotes, with cell viability being measured using a modified MTS assay (Ganguly et al., 2006b). Briefly, exponential-phase promastigotes $\left(2 \times 10^{5}\right.$ cells in $200 \mu \mathrm{M} 199$ medium per well) were incubated with artemisinin $(0-0.5 \mathrm{mM})$ for $48 \mathrm{~h}$. Pentamidine $(0-$ $10 \mu \mathrm{M})$ and miltefosine $(0-50 \mu \mathrm{M})$ served as reference drugs, as well as $0.25 \%$ DMSO, which represented the highest concentration of DMSO present in the artemisinin $(0.5 \mathrm{mM})$. After treatment, parasite viability was measured using 3-(4, 5-dimethylthiazol-2-yl)-5-(3carboxymethaloxyphenyl)-2-(4-sulfonyl)-2H-tetrazolium inner salt (MTS). The results were expressed as $\mathrm{IC}_{50}$ values, i.e. the concentration that inhibited $50 \%$ of cell growth, enumerated by graphic extrapolation using GRAPHPAD PRISM software (version 4).

Evaluation of ex vivo anti-amastigote activity. Exponentialphase, non-adherent THP1 monocytes seeded in eight-well slides (BD Biosciences) $\left(5 \times 10^{4}\right.$ cells in $200 \mu \mathrm{l}$ per well $)$ were incubated with $20 \mathrm{nM}$ phorbol myristate acetate at $37^{\circ} \mathrm{C}, 5 \% \mathrm{CO}_{2}$ for at least $12 \mathrm{~h}$. Adherent macrophages were equilibrated in phorbol myristate acetate-free medium for at least $24 \mathrm{~h}$ and then incubated with stationary-phase promastigotes for at least $3 \mathrm{~h}$ at $37{ }^{\circ} \mathrm{C}, 5 \% \mathrm{CO}_{2}$. After removal of non-phagocytosed promastigotes, infected macrophages were incubated with artemisinin $(0-250 \mu \mathrm{M})$ for $48 \mathrm{~h}$ at $37{ }^{\circ} \mathrm{C}, 5 \% \mathrm{CO}_{2}$. Cells were then fixed, stained with Giemsa and examined microscopically for intracellular amastigotes. At least 100 macrophages per well were counted to calculate the percentage of infected macrophages (Dube et al., 2005).

To evaluate the safety index of artemisinin, murine peritoneal macrophages were lavaged from pre-primed BALB/c mice $(2 \%$ starch, $2 \mathrm{ml}$ per mouse) and seeded in 96-well plates $\left(2 \times 10^{5}\right.$ in $200 \mu \mathrm{l}$ per well) at $37{ }^{\circ} \mathrm{C}, 5 \% \mathrm{CO}_{2}$. After removal of non-adherent cells, macrophages were incubated with artemisinin $(0-0.5 \mathrm{mM})$ for $48 \mathrm{~h}$ at $37{ }^{\circ} \mathrm{C}, 5 \% \mathrm{CO}_{2}$, and its effect on macrophage viability was enumerated using an MTS assay as described above.

Analysis of phosphatidylserine externalization. Double staining for annexin V-FITC and propidium iodide (PI) was performed as described previously (Dutta et al., 2007a). Briefly, promastigotes were incubated with an $\mathrm{IC}_{50}$ dose of artemisinin $(160 \mu \mathrm{M})$ for 24 and $48 \mathrm{~h}$ at $24{ }^{\circ} \mathrm{C}$ and cells were centrifuged ( $1000 \mathrm{~g}$ for $10 \mathrm{~min}$ ), washed twice in $0.02 \mathrm{M}$ PBS ( $\mathrm{pH}$ 7.2) and resuspended in annexin $\mathrm{V}$ binding buffer [10 mM HEPES/NaOH (pH 7.4), $140 \mathrm{mM} \mathrm{NaCl}, 2.5 \mathrm{mM} \mathrm{CaCl}$ ]. Annexin V-FITC and PI $\left(1 \mu \mathrm{g} \mathrm{ml}^{-1}\right)$ were then added according to the manufacturers' instructions and incubated for $30 \mathrm{~min}$ in the dark at 20$25{ }^{\circ} \mathrm{C}$. Data acquisition was carried out using a FACSCalibur flow cytometer (BD Biosciences) and analysed with CELLQUEST PRO software.
Analysis of mitochondrial transmembrane potential. To assess the mitochondrial transmembrane electrochemical gradient $\left(\Delta \psi_{\mathrm{m}}\right)$, a cell-permeable, cationic and lipophilic dye, JC-1, was used. This probe aggregates within mitochondria and fluoresces red at higher transmembrane potentials. However, at lower transmembrane potentials, JC-1 cannot accumulate within the mitochondria and instead remains in the cytosol as monomers, which fluoresce green. Therefore, the ratio of red to green fluorescence gives a measure of the transmembrane electrochemical gradient (Verma et al., 2007).

Accordingly, to evaluate the effect of artemisinin on mitochondrial membrane potential, promastigotes were incubated with $160 \mu \mathrm{M}$ artemisinin for 24 and $48 \mathrm{~h}$ at $24{ }^{\circ} \mathrm{C}$. Drug-treated and control cells were stained at corresponding time points with JC-1 (3 $\mu \mathrm{M}$ in PBS) and analysed by flow cytometry as described previously (Dutta et al., 2007b). Briefly, after drug treatment, cells were washed in PBS and incubated with JC-1 for $15 \mathrm{~min}$ at $20-25{ }^{\circ} \mathrm{C}$. Data acquisition was carried out using a FACSCalibur and analysed using CELLQUEST PRO software. Heat-killed promastigotes, representative of cells with depolarized mitochondria, were processed and analysed similarly. In situ detection of DNA fragmentation by terminal deoxynu-
cleotidyl transferase (TdT)-mediated dUTP nick end labelling (TUNEL). In situ detection of DNA fragments following treatment of promastigotes with an $\mathrm{IC}_{50}$ concentration of artemisinin $(160 \mu \mathrm{M})$ for 24 and $48 \mathrm{~h}$ at $24{ }^{\circ} \mathrm{C}$ was measured by TUNEL using a Cell Death Detection kit (Roche) according to the manufacturer's instructions. Cells were then washed, fixed with paraformaldehyde (2\% in PBS, $\mathrm{pH} 7.4$ ) and kept on ice for $1 \mathrm{~h}$. Thereafter, $2 \times 10^{5}$ cells were centrifuged (1800 $\boldsymbol{g}$ for $5 \mathrm{~min}$ ), resuspended in $10 \mu \mathrm{PBS}$, spotted on to slides and air dried; they were washed with PBS and incubated with $\mathrm{H}_{2} \mathrm{O}_{2}(3 \%$ in methanol) for $10 \mathrm{~min}$ at $4{ }^{\circ} \mathrm{C}$. The slides were washed again with PBS, placed on ice and permeabilized with freshly prepared, chilled $0.1 \%$ sodium citrate in $0.1 \%$ Triton X-100 solution for 15 min. Cells were washed twice with $\mathrm{PBS}$, after which a $25 \mu \mathrm{l}$ reaction mixture containing TdT and dUTP-FITC (Cell Death Detection kit; Roche) was added. The slides were then incubated in a humidified chamber at $37^{\circ} \mathrm{C}$ for $1 \mathrm{~h}$, washed with PBS and $25 \mu$ converter POD (anti-fluorescein antibody conjugated to horseradish peroxidase, Cell Death Detection kit; Roche) was added and incubated for $30 \mathrm{~min}$ at $37^{\circ} \mathrm{C}$. Finally, $25 \mu \mathrm{l}$ diaminobenzidine (Cell Death Detection kit; Roche) was added and slides were incubated at $4{ }^{\circ} \mathrm{C}$ for $10 \mathrm{~min}$, washed with deionized water and observed microscopically under an oil-immersion objective; at least 20 microscope fields were observed for each sample. In parallel, after addition of the reaction mixture containing TdT and dUTP-FITC, cells were incubated at $37{ }^{\circ} \mathrm{C}$ for $1 \mathrm{~h}$; cells were then washed and resuspended in PBS before data acquisition on a FACSCalibur and analysis using CELLQUEST PRO software.

Effect of artemisinin on the cell cycle. Parasites $\left(1 \times 10^{6}\right.$ cells $)$ were treated with an $\mathrm{IC}_{50}$ dose of artemisinin $(160 \mu \mathrm{M})$ for 24 and $48 \mathrm{~h}$ at $24{ }^{\circ} \mathrm{C}$; at each time point, cells were fixed in chilled $70 \%$ ethanol and kept at $-20{ }^{\circ} \mathrm{C}$ until analysis. After washing the cells in PBS, the resultant pellet was resuspended in $500 \mu$ l DNase-free RNase $\left(200 \mu \mathrm{g} \mathrm{ml}^{-1}\right)$ and incubated for $1 \mathrm{~h}$ at $37^{\circ} \mathrm{C}$. Cells were then stained with PI $\left(40 \mu \mathrm{g} \mathrm{ml}^{-1}\right)$ and incubated in the dark for $20 \mathrm{~min}$ at 20 $25{ }^{\circ} \mathrm{C}$. Data acquisition was carried out using a FACSCalibur and analysed using CELLQUEST PRO software.

\section{RESULTS AND DISCUSSION}

\section{Anti-promastigote activity of artemisinin}

The leafy portion of Artemisia sp. (Chinese name qinghao) was used in traditional Chinese medicine as early as $168 \mathrm{BC}$, 
but it was not until 1972 that scientists purified and determined the chemical structure of this sesquiterpene lactone and designated it artemisinin (Meshnick, 2002). The effect of artemisinin on the viability of promastigotes was evaluated using an MTS assay wherein the conversion of MTS to formazan by mitochondrial enzymes in the presence of the electron coupler phenazine methosulfate served as an indicator of cell viability; thus, a decrease in formazan production indicated decreased cell viability and vice versa (Ganguly et al., 2006b). Treatment of promastigotes with artemisinin $(0-0.5 \mathrm{mM}$ for $48 \mathrm{~h})$ demonstrated a dose-dependent inhibition of parasite growth and an $\mathrm{IC}_{50}$ value in promastigotes of $160 \mu \mathrm{M}$. In parallel, the $\mathrm{IC}_{50}$ values of the reference drugs miltefosine and pentamidine were evaluated as 21.0 and $1.25 \mu \mathrm{M}$, respectively, which correlated with previous reports (Ganguly et al., 2006b). The addition of $0.25 \%$ DMSO caused no change in parasite viability (data not shown).

The $\mathrm{IC}_{50}$ value of artemisinin agreed with previous reports using $L$. donovani promastigotes (Avery et al., 2003) in which artemisinin and over 70 of its derivatives were studied. Some derivatives had an $\mathrm{IC}_{50}$ value as low as $1.4 \mu \mathrm{M}$, suggesting that, with minor modifications, the anti-leishmanial potency of artemisinin could be enhanced; however, these need to be tested in the classical amastigote-macrophage model and their safety profile evaluated. With regard to Leishmania strains responsible for cutaneous leishmaniasis, artemisinin was more potent, with an $\mathrm{IC}_{50}$ value of $750 \mathrm{nM}$ for promastigotes and 3$30 \mu \mathrm{M}$ for intracellular amastigotes (Yang \& Liew, 1993).

\section{Anti-amastigote activity of artemisinin}

During Leishmania infection, promastigotes transform into amastigotes within phagolysosomal vacuoles of macrophages. Accordingly, the anti-leishmanial activity of artemisinin $(0-250 \mu \mathrm{M}$ for $48 \mathrm{~h})$ was tested against intracellular amastigotes in $L$. donovani-infected THP1 cells. The infection rate of artemisinin-treated macrophages was normalized to $100 \%$ for further analysis of the results. Artemisinin showed a dose-dependent reduction in parasitic load and an $\mathrm{IC}_{50}$ value of $22 \mu \mathrm{M}$, which was 7 fold lower than the $\mathrm{IC}_{50}$ value obtained in promastigotes.

To evaluate the safety index of artemisinin, its effect $(0$ $0.5 \mathrm{mM}$ for $48 \mathrm{~h}$ ) on viability of murine peritoneal macrophages was evaluated using an MTS assay. Macrophage viability remained unaffected up to $0.25 \mathrm{mM}$; at the highest concentration of $0.5 \mathrm{mM}$, cell viability was $60 \%$ and therefore the $\mathrm{IC}_{50}$ value of artemisinin in macrophages was at least 22-fold higher than in amastigotes.

The $\mathrm{IC}_{50}$ value of artemisinin as an anti-malarial drug is in the nanomolar range $(4.2-16.2 \mathrm{nM})$ whereas, for antileishmanial activity, micromolar concentrations are required. However, the safety index of the drug as an anti-leishmanial is high and, as oral, parenteral and rectal dosages can achieve micromolar concentrations (Räth et al.,
2004), artemisinin could well be considered a potential anti-leishmanial drug. Artemisinin compounds have also been shown to inhibit in vitro growth of Trypanosoma cruzi and Trypanosoma brucei subsp. rhodesiense at micromolar concentrations, providing evidence of its expanding therapeutic potential (Mishina et al., 2007).

\section{Artemisinin induces phosphatidylserine externalization in $L$. donovani promastigotes}

Artesunate, an analogue of artemisinin, has been shown to trigger apoptosis in tumour cells by both p53-dependent and -independent pathways (Efferth, 2007). In parasites, apoptosis, or programmed cell death, appears to be the predominant form of cell death, as has been observed in kinetoplastids (Arnoult et al., 2002) in response to diverse stimuli, e.g. heat shock, chemotherapeutic agents such as pentostam and amphotericin $\mathrm{B}$, oxidants such as $\mathrm{H}_{2} \mathrm{O}_{2}$, serum depletion and plant extracts such as Aloe vera leaf exudate (Dutta et al., 2007b).

Following an apoptotic stimulus, phosphatidylserine present in the inner leaflet of the plasma membrane flips out to the outer leaflet of the plasmalemma; thus, externalization of phosphatidylserine is considered to be a marker of apoptosis (Debrabant \& Nakhasi, 2003). The binding of annexin $\mathrm{V}, \quad \mathrm{a} \mathrm{Ca}^{2+}$-dependent phospholipid-binding protein known to have a strong affinity towards phosphatidylserine, is a proven measure of apoptosis. To distinguish apoptotic cell death from necrotic cell death, cells were counterstained with PI, a non-permeable stain with an affinity for nucleic acids, as it selectively enters necrotic cells. Therefore, co-staining of annexin V and PI can differentiate between cells undergoing early apoptosis (annexin V-positive, PI-negative) or necrosis (PI-positive, annexin V-negative) and live cells (PI- and annexin Vnegative).

In untreated promastigotes, the degree of binding of annexin $\mathrm{V}$ at 24 and $48 \mathrm{~h}$ was 2.31 and $2.35 \%$, respectively. Following treatment of promastigotes with artemisinin at its IC $\mathrm{IC}_{50}$ value of $160 \mu \mathrm{M}$ for 24 and $48 \mathrm{~h}$, the percentage of annexin V-positive cells increased to $7.62 \%$ at $24 \mathrm{~h}$ and $38.97 \%$ at $48 \mathrm{~h}$ (Fig. 1, lower-right quadrant). The percentage of PI-stained cells (Fig. 1, upper-left quadrant) ranged from 0.19 to $0.55 \%$, indicating that artemisinin exerts its anti-leishmanial activity primarily via apoptosis.

\section{Artemisinin induces depolarization of mitochondrial transmembrane potential in promastigotes}

Maintenance of the mitochondrial transmembrane potential is essential for parasite survival, as Leishmania has a single mitochondrion. JC-1, a cationic lipophilic dye, becomes concentrated in the mitochondria in proportion to the membrane potential wherein it forms J-aggregates, which emit red fluorescence at $590 \mathrm{~nm}$, whereas, during depolarization, the dye remains as a monomer, emitting 


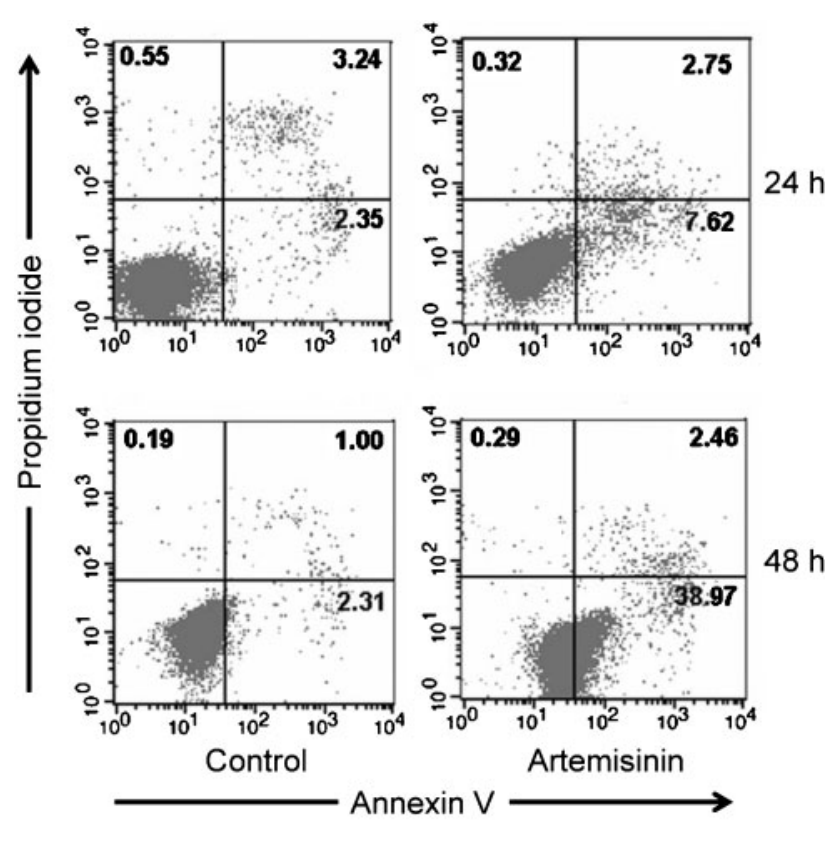

Fig. 1. Externalization of phosphatidylserine in artemisinin-treated promastigotes. Promastigotes (strain MHOM/IN/83/AG83; $1 \times 10^{6}$ cells $\mathrm{ml}^{-1}$ ) were incubated with an $\mathrm{IC}_{50}$ dose of artemisinin $(160 \mu \mathrm{M})$ for 24 and $48 \mathrm{~h}$, co-stained with PI and annexin V-FITC and analysed by flow cytometry as described in Methods. The lower-left quadrant indicates the percentage of unstained cells, the upper-left shows PI-positive cells, the lower-right shows annexin V-stained cells and the upper-right shows PI- and annexin Vpositive cells. The figure shows a representative result of at least three experiments.

green fluorescence at $530 \mathrm{~nm}$. Therefore, the ratio of red:green fluorescence serves as an indicator of the mitochondrial energy state of the parasite.

The loss of mitochondrial membrane potential is a characteristic feature of metazoan apoptosis and has been observed to play a key role in drug-induced death in protists such as Leishmania (Sen et al., 2004). In untreated cells, the red:green fluorescence ratio at 24 and $48 \mathrm{~h}$ was 0.978 and 1.95 , respectively. However, the addition of $160 \mu \mathrm{M}$ artemisinin caused a loss of mitochondrial membrane potential, blocking JC-1 entry to the mitochondria, leaving the JC-1 monomers to fluoresce green within the cytoplasm. This was reflected in the red:green fluorescence ratio, which decreased to 0.521 and 0.55 following drug treatment for 24 and $48 \mathrm{~h}$, respectively (Fig. 2).

In a dot-plot analysis, JC-1 fluorescence was seen in both the FL-2 (R2-gated population) and FL-1 (R3-gated population) channels. The $\mathrm{R} 2$ gate was predominantly red fluorescence and reflected the non-apoptotic (healthy) population, whereas the R3 gate was prominently green fluorescence and reflected the apoptotic cell population. In heat-killed promastigotes, $10.44 \%$ of cells were within the

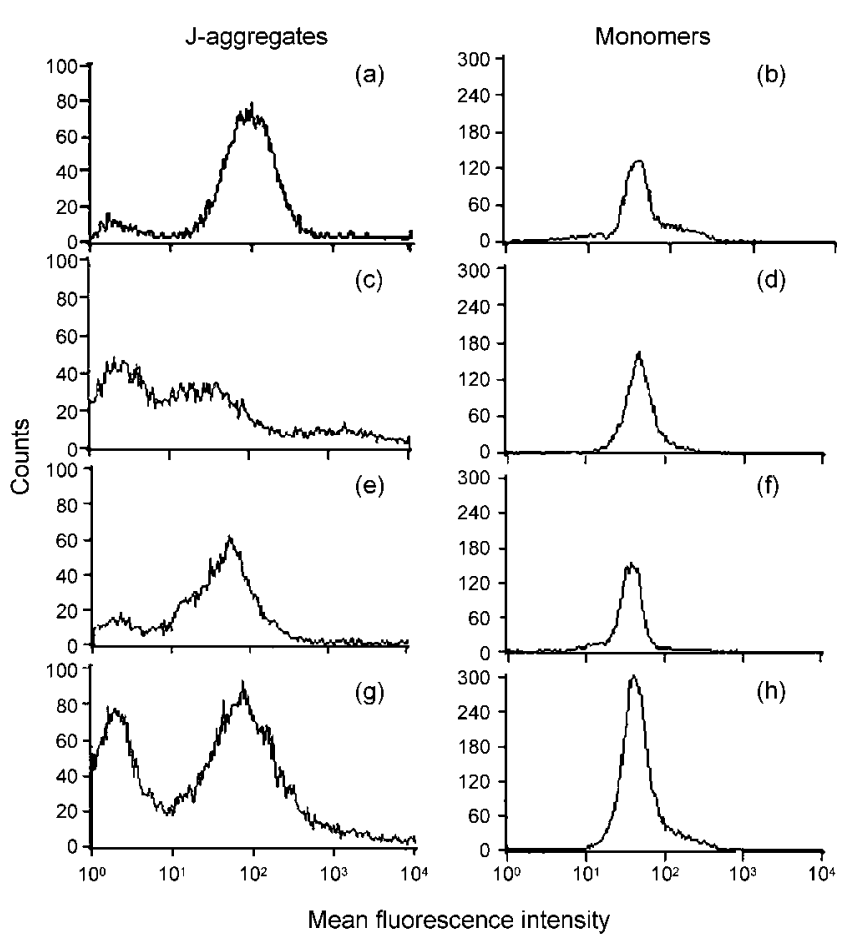

Fig. 2. Effect of artemisinin on mitochondrial function. Promastigotes (strain MHOM/IN/83/AG83, $1 \times 10^{6}$ cells ml $^{-1}$ ) were treated with an $\mathrm{IC}_{50}$ dose of artemisinin $(160 \mu \mathrm{M})$ for $24(\mathrm{a}-\mathrm{d})$ and $48 \mathrm{~h}$ $(\mathrm{e}-\mathrm{h})$ and stained with JC-1 as described in Methods. The presence of J-aggregates ( $\mathrm{a}, \mathrm{c}, \mathrm{e}, \mathrm{g}$ ) (red fluorescence, $590 \mathrm{~nm}$ ) and monomers ( $b, d, f, h$ ) (green fluorescence, $530 \mathrm{~nm}$ ) for cells left untreated $(a, b, e, f)$ or treated with artemisinin $(c, d, g, h)$ is shown.

R2 gate and $82.89 \%$ within the R3 gate, confirming detection of depolarized membrane potential. In untreated cells at $24 \mathrm{~h}$, the R2 gate contained $88.16 \%$ of the population, whereas the R3 gate contained only $7.27 \%$ of the population. With the addition of artemisinin $(160 \mu \mathrm{M}$ for $24 \mathrm{~h}$ ) the percentage positivity in the R2 gate decreased to $30.63 \%$ and the R3 population increased dramatically to $49.44 \%$. At $48 \mathrm{~h}$, untreated cells had $75.35 \%$ in the R2 gate and $21.18 \%$ in the R3 gate. The addition of artemisinin $(160 \mu \mathrm{M}$ for $48 \mathrm{~h})$ caused a decrease in the R2-gated population to $53.65 \%$ whilst, in the R3 gate, the percentage positivity increased to $34.55 \%$. Taken together, these data indicated that artemisinin caused induction of apoptosis associated with depolarization of the mitochondria.

The nature of the trigger for artemisinin-mediated loss of mitochondrial membrane potential remains unclear. The anti-malarial action of artemisinin and its derivatives is proposed to be via its reaction with iron (ferrous compounds) (Golenser et al., 2006). The haemoglobin within infected erythrocytes is digested by the parasite, and haem is released and neutralized by polymerization into haemazoin, with a high $\mathrm{Fe}^{2+}$ content. When artemisinin comes into contact with high iron concentrations, a chemical reaction is triggered that generates free radicals, 
which are primarily responsible for the anti-malarial action (Golenser et al., 2006). It remains to be seen whether a similar scenario occurs within the Leishmania parasite.

\section{Artemisinin induces in situ DNA nicking in L. donovani promastigotes}

Degradation of nuclear DNA into nucleosomal units is one of the hallmarks of apoptotic cell death. To evaluate the endonuclease activity of artemisinin $(160 \mu \mathrm{M}$ for 24 and $48 \mathrm{~h}, 24^{\circ} \mathrm{C}$ ), in situ TUNEL staining was performed. In parasites treated with artemisinin for $24 \mathrm{~h}$, brown deposits representing incorporated TdT-labelled nuclei were observed, which increased further when parasites were incubated with artemisinin for $48 \mathrm{~h}$, indicating nicking of the DNA (data not shown).

The occurrence of DNA nicking was also detected by quantifying the binding of FITC-labelled dUTP to the nicked ends via TdT, as the proportion of DNA nicks is directly proportional to the fluorescence obtained. Promastigotes treated with artemisinin $(160 \mu \mathrm{M}$ for $24 \mathrm{~h})$ caused an increase in nuclear DNA fragmentation, as the dUTP-FITC binding following artemisinin treatment for $24 \mathrm{~h}$ increased from a baseline mean fluorescence intensity of 35.96 in untreated cells to 110.27 , thus confirming that the leishmanicidal activity of artemisinin occurs via apoptosis (Fig. 3).

\section{Artemisinin induces sub- $G_{0} / G_{1}$ phase cell-division arrest}

Flow cytometric analysis after cell permeabilization and labelling with PI was used to quantify the percentage of pseudohypodiploid cells. In a given cell, the amount of bound dye correlates with the DNA content and thus DNA

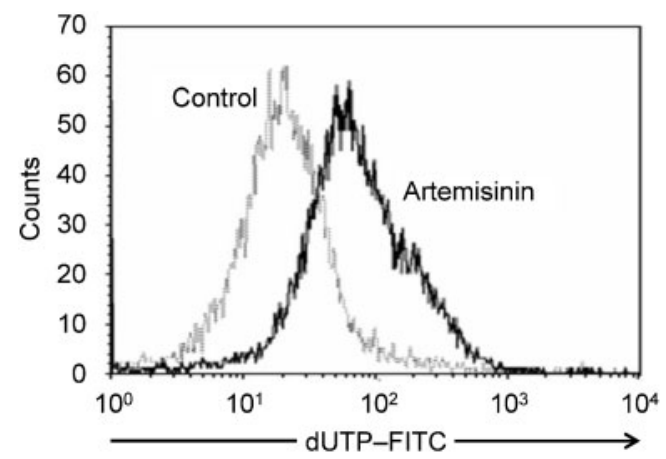

Fig. 3. Analysis of TUNEL positivity in artemisinin-treated promastigotes. Promastigotes (strain MHOM/IN/83/AG83; $1 \times 10^{6}$ cells $\mathrm{ml}^{-1}$ ) incubated with an $\mathrm{IC}_{50}$ dose of artemisinin $(160 \mu \mathrm{M}$ for $24 \mathrm{~h})$ were stained with dUTP-FITC as described in Methods. The grey trace shows a control without artemisinin. The figure shows a representative profile of at least three experiments.
Table 1. Effect of artemisinin on the cell cycle of $L$. donovani promastigotes

L. donovani promastigotes $\left(1 \times 10^{6}\right.$ cells $\left.\mathrm{ml}^{-1}\right)$ were treated with $160 \mu \mathrm{M}$ artemisinin for 24 or $48 \mathrm{~h}$ and processed for cell-cycle analysis as described in Methods. Values are percentages.

\begin{tabular}{|lccc|}
\hline Group & Sub- $\mathbf{G}_{\mathbf{0}} / \mathbf{G}_{\mathbf{1}}(\mathbf{M} \mathbf{1})$ & $\mathbf{G}_{\mathbf{0}} / \mathrm{G}_{\mathbf{1}}(\mathbf{M} \mathbf{2})$ & $\mathbf{S}$ and $\mathbf{G}_{\mathbf{2}} / \mathbf{M}(\mathbf{M} \mathbf{3})$ \\
\hline $\mathbf{2 4} \mathbf{h}$ & & & \\
Control & 3.62 & 55.92 & 41.03 \\
Artemisinin & 10.86 & 62.28 & 27.45 \\
$\mathbf{4 8} \mathbf{h}$ & & & \\
Control & 3.03 & 67.78 & 29.65 \\
Artemisinin & 33.11 & 57.42 & 12.03 \\
& & & \\
\hline
\end{tabular}

fragmentation in apoptotic cells translates into fluorescence intensity lower than that of $G_{0} / G_{1}$ cells, i.e. a sub- $G_{0} / G_{1}$ peak. In promastigotes incubated with artemi$\operatorname{sinin}(160 \mu \mathrm{M}$ for $24 \mathrm{~h})$, the proportion of cells in the sub$\mathrm{G}_{0} / \mathrm{G}_{1}$ phase increased to $10.86 \%$ compared with $3.62 \%$ of controls (Table 1). Following $48 \mathrm{~h}$ of drug treatment, the proportion of cells in the sub- $G_{0} / G_{1}$ phase increased further to $33.11 \%$ compared with $3.03 \%$ in control cells. This increase in sub- $\mathrm{G}_{0} / \mathrm{G}_{1}$ phase was accompanied by a decrease in the number of cells in the $\mathrm{G}_{2} / \mathrm{M}$ phase compared with untreated cells, with values of 27.45 vs $41.03 \%$ at $24 \mathrm{~h}$ and 12.03 vs $29.65 \%$ at $48 \mathrm{~h}$ (Table 1). Taken together, the increased proportion of cells in the sub- $G_{0} / G_{1}$ phase confirmed that artemisinininduced apoptosis in promastigotes resulted in DNA degradation.

Apoptotic-like changes have been shown to mediate the action of several anti-leishmanial drugs including miltefosine (Verma et al., 2007), amphotericin B (Moreira et al., 1996) and Aloe vera leaf exudate (Dutta et al., 2007a, b). In this study, we have shown that artemisinin has a leishmanicidal effect against both promastigotes and amastigotes of $L$. donovani, with cell death being via apoptosis. The 7 -fold lower $\mathrm{IC}_{50}$ in amastigotes compared with promastigotes suggests that its leishmanicidal activity is enhanced by immunomodulation of macrophages. As the pharmacokinetics of artemisinin have been evaluated extensively and its oral bioavailability proven, the stage is set to study the potential of artemisinin as an antileishmanial compound in animal models, with the potential to strengthen the therapeutic control of leishmaniasis.

\section{ACKNOWLEDGEMENTS}

This work received financial assistance from the Life Sciences Research Board, DRDO, and the University Grants Commission, Government of India. S. G. and G.M. are recipients of a Senior Research fellowship from the University Grants Commission and the Council of Scientific and Industrial Research, Government of India, respectively. 


\section{REFERENCES}

Arnoult, D., Akarid, K., Grodet, A., Petit, P. X., Estaquier, J. \& Ameisen, J. C. (2002). On the evolution of programmed cell death: apoptosis of the unicellular eukaryote Leishmania major involves cysteine proteinase activation and mitochondrion permeabilization. Cell Death Differ 9, 65-81.

Avery, M. A., Muraleedharan, K. M., Desai, P. V., Bandyopadhyaya, A. K., Furtado, M. M. \& Tekwani, B. L. (2003). Structure-activity relationships of the antimalarial agent Artemisinin. 8. Design, synthesis, and CoMFA studies toward the development of artemisinin-based drugs against leishmaniasis and malaria. J Med Chem 46, 4244-4258.

Bhakuni, R. S., Jain, D. C., Sharma, R. P. \& Kumar, S. (2001). Secondary metabolites of Artemisia annua and their biological activity. Curr Sci 80, 35-48.

Croft, S. L., Sundar, S. \& Fairlamb, A. H. (2006). Drug resistance in leishmaniasis. Clin Microbiol Rev 19, 111-126.

Debrabant, A. \& Nakhasi, H. (2003). Programmed cell death in trypanosomatids: is it an altruistic mechanism for survival of the fittest? Kinetoplastid Biol Dis 2, 7.

Dube, A., Singh, S., Sundar, S. \& Singh, N. (2005). Refractoriness to the treatment of sodium stibogluconate in Indian kala-azar field isolates persist in in vitro and in vivo experimental models. Parasitol Res 96, 216-223.

Dutta, A., Bandyopadhyay, S., Mandal, C. \& Chatterjee, M. (2007a). Aloe vera leaf exudate induces a caspase independent cell death in Leishmania donovani promastigotes. J Med Microbiol 56, 629-636.

Dutta, A., Mandal, G., Mandal, C. \& Chatterjee, M. (2007b). In vitro antileishmanial activity of Aloe vera leaf exudate: a potential herbal therapy in leishmaniasis. Glycoconj J 24, 81-86.

Efferth, T. (2007). Antiplasmodial and antitumor activity of artemisinin - from bench to bedside. Planta Med 73, 299-309.

Ganguly, S., Bandyopadhyay, S., Bera, A. \& Chatterjee, M. (2006a). Anti-promastigote activity of an ethanolic extract of leaves of Artemisia indica. Indian J Pharmacol 38, 64-65.

Ganguly, S., Bandyopadhyay, S., Sarkar, A. \& Chatterjee, M. (2006b). Development of a semi-automated colorimetric assay for screening anti-leishmanial agents. J Microbiol Methods 66, 79-86.

Golenser, J., Waknine, J. H., Krugliak, M., Hunt, N. H. \& Grau, G. E. (2006). Current perspectives on the mechanism of action of artemisinins. Int J Parasitol 36, 1427-1441.

Meshnick, S. R. (2002). Artemisinin: mechanisms of action, resistance and toxicity. Int J Parasitol 32, 1655-1660.

Mishina, Y. V., Krishna, S., Haynes, R. K. \& Meade, J. C. (2007). Artemisinins inhibit Trypanosoma cruzi and Trypanosoma brucei rhodesiense in vitro growth. Antimicrob Agents Chemother 51, 1852-1854.

Moreira, M. E. C., Del Portillo, H. A., Milder, R. V., Balanco, J. M. F. \& Barcinski, M. A. (1996). Heat shock induction of apoptosis in promastigotes of the unicellular organism Leishmania (Leishmania) amazonensis. J Cell Physiol 167, 305-313.

Murray, H. W., Berman, J. D., Davies, C. R. \& Saravia, N. G. (2005). Advances in leishmaniasis. Lancet 366, 1561-1577.

Räth, K., Taxis, K., Walz, G., Gleiter, C. H., Li, S. M. \& Heide, L. (2004). Pharmacokinetic study of artemisinin after oral intake of a traditional preparation of Artemisia annua L. (annual wormwood). Am J Trop Med Hyg 70, 128-132.

Sen, N., Das, B. B., Ganguly, A., Mukherjee, T., Tripathi, G., Bandopadhyay, S., Rakshit, S., Sen, T. \& Majumder, H. K. (2004). Camptothecin induced mitochondrial dysfunction leading to programmed cell death in unicellular hemoflagellate Leishmania donovani. Cell Death Differ 11, 924-936.

Sen, R., Bauri, A., Chattopadhyay, S. \& Chatterjee, M. (2007). Antipromastigote activity of the malabaricones of Myristica malabarica (rampatri). Phytother Res 21, 592-595.

Sundar, S. \& Chatterjee, M. (2006). Visceral leishmaniasis - current therapeutic modalities. Indian J Med Res 123, 345-352.

Verma, N. K., Singh, G. \& Dey, C. S. (2007). Miltefosine induces apoptosis in arsenite- resistant Leishmania donovani promastigotes through mitochondrial dysfunction. Exp Parasitol 116, 1-13.

Yang, D. M. \& Liew, F. Y. (1993). Effects of qinghaosu (artemisinin) and its derivatives on experimental cutaneous leishmaniasis. Parasitology 106, 7-11. 